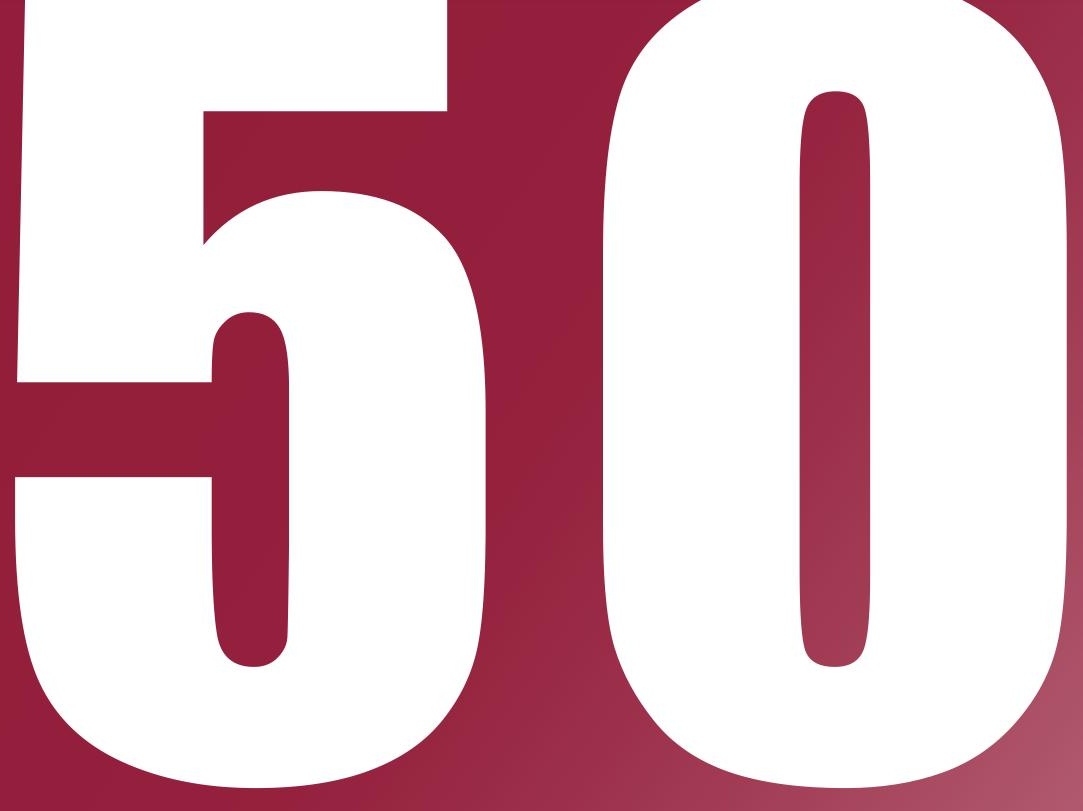

ÁMBITOS

REVISTA

INTERNACIONAL

DE

COMUNICACIÓN

$\mathbf{N}^{\circ} \mathbf{5 0}$

EDICIÓN OTOÑO

2020

ISSN: 1139-1979

E-ISSN: 1988-5733

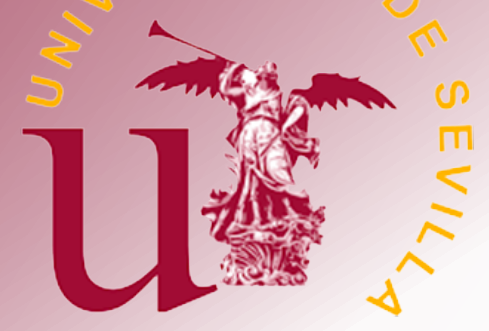




\section{INDICE}

EDITORIAL EDITORIAL

Presentación del Monográfico. Comunicación y juventud. Nuevos medios, representación, recepción y participación en contenidos de entretenimiento e información

Presentation of the monograph. Communication and youth. New media, representation, reception and participation in entertainment and information content.

Juan Francisco Gutiérrez Lozano, Francisco Javier Ruiz del Olmo

7-9

\section{MONOGRÁFICO MONOGRAPH}

El consumo audiovisual de la Generación Z. El predominio del vídeo online sobre la televisión tradicional The audiovisual consumption of Generation $Z$. The predominance of online video over traditional television

La imagen de los jóvenes en las estrategias transmedia de las series de televisión: el caso de Skam España en Instagram

The image of young people in transmedia strategies of TV series: the case of Skam España on Instagram

Sergio Jesús Villén Higueras, Francisco Javier Ruiz del Olmo

La penetración de Netflix en el público español ¿cuestiona el modelo televisivo tradicional?

Does the arrival of Netflix in the Spanish audience challenge the traditional television model?

Javier Bustos Díaz

49-61

Generación Z y consumo de información política: entre la televisión y los nuevos formatos mediáticos Generation $Z$ and consumption of political information: between television and new media formats

Ruth Gómez de Travesedo Rojas, Marta Gil Ramírez

$62-79$

Actualidad y comedia: El éxito de El Intermedio y La Resistencia entre los espectadores jóvenes

Information and comedy: The Success of El Intermedio and La Resistencia for young audiences

Inmaculada Concepción Aguilera García

80-95 
El efecto socializador de articular un espacio de comunidad virtual en el ecosistema del aula

The socializing effect of creating a virtual community space in the classroom environment

Lorea Ariadna Ruiz Gómez, Mónica Hinojosa Becerra, Francisco Javier Ruiz San Miguel

Juventude ciberativista e educação: reflexões sobre um jeito hacker de ser

Cyber activity youth and Education: reflections on a hacker way of being

Carla Azevedo de Aragão, Pietro Matheus Bompet Fontoura Alves, Karina Moreira Menezes

La risa grotesca en la obra de Bob Dylan: análisis de la Bacanal y el Festín Carnavalesco en la trilogía folk-rock eléctrica

Grotesque Laughter in Bob Dylan's Work: Analysis of The Bacchanal and the Carnival Feast in the Electric Folk-rock Trilogy

Jesús Albarrán Ligero

El papel del intertexto en el videojuego. Una partida, mil y una historias

Intertext in video games. A game, thousand and one stories

Rocío Serna-Rodrigo

145-158

\section{ÁmBitos PERSONALES PERSONAL ÁmBITOS}

El auge de Twitch: nuevas ofertas audiovisuales y cambios del consumo televisivo entre la audiencia juvenil The rise of Twitch: New audiovisual offers and the transformation of Television consumption among young audiences

\section{ARTÍCULOS ARTICLES}

La recepción de los medios de comunicación para residentes rusos en la Costa del Sol

Mass media reception by Russian residents on the Costa del Sol

Natalia Meléndez Malavé, José Carlos Pozo García

176-192

La calidad periodística en la cobertura de terremotos: Caso Ecuador

Journalistic quality in earthquake coverage: The case of Ecuador

Juan Pablo Arrobo-Agila, Mendoza María, Ignacio Aguaded

La credibilidad publicitaria en la nueva esfera mediática: los universitarios y los medios

Advertising credibility in the new media sphere: university students and the media 
Arco iris en medios brasileños: percepciones sociales sobre una campaña publicitaria LGBTQIA+

Rainbow in Brazilian media: social perceptions of an LGBTQIA+ advertising campaign

Leonardo Ferreira Batista, José Geraldo de Araújo Ramalho Filho

224-239

Rituales y comunicación política: la toma de posesión de los presidentes autonómicos españoles

Rituals and political communication: the Spanish autonomous Presidents inauguration

Ricardo Domínguez García

240-258

RESEÑAS REVIEWS

Una mirada diferente para hacer periodismo

A different look for making journalism

Guillermo Paredes-Otero

259-261

Periodismo y tecnología: una simbiosis continua

Journalism and technology: a continuous symbiosis

Luisa Graciela Aramburú Moncada

262-265

Una propuesta metodológica para impartir la asignatura de redacción periodística

Journalism and technology: a continuous symbiosis

Noelia Ruiz-Alba

266-268 


\title{
La risa grotesca en la obra de Bob Dylan: análisis de la Bacanal y el Festín Carnavalesco en la trilogía folk-rock eléctrica
}

\author{
Grotesque Laughter in Bob Dylan's Work: Analysis of The Bacchanal and \\ the Carnival Feast in the Electric Folk-rock Trilogy
}

\author{
Jesús Albarrán Ligero \\ Universidad de Sevilla | Calle San Fernando s/n 41004 Sevilla| España \\ | https://orcid.org/0000-0002-6477-4879 | jesalblig@gmail.com
}

Fechas | Recepción:29/04/2020 | Aceptación: 20/07/0000 | Publicación final: 15/10/0000

\section{Resumen}

A través de la sordidez, la risa y el horror, la noción de lo grotesco se ha plasmado en el arte de manera patente desde el siglo XVI. Lo grotesco ha servido tradicionalmente para nombrar lo "innombrable" con una carcajada. La intención de este artículo es doble. Por un lado, este estudio pretende ahondar en la dimensión existencialista que transpira la obra creativa de Dylan a partir de 1965, además de atender a la definición de lo grotesco como una tendencia artística transhistórica que dispone un imaginario original a partir de la monstruosidad y el exceso. Por otro, esta investigación aborda un análisis sobre la dimensión grotesca de inercia existencialista en el caso de los tres discos eléctricos publicados por Bob Dylan - Bringing It All Back Home, Highway 61 Revisited y Blonde on Blonde. A través de un estudio comparativo de sus versos y las nociones estéticas dispuestas principalmente por Wolfgang Kayser y Mijaíl Bajtín, se trazará una taxonomía gradual de lo grotesco y se aplicará a las letras que

\section{Abstract}

Through sordidness, laughter and horror, the notion of the grotesque has been embodied in art patently since the 16th century. The grotesque has traditionally served to name the "unmentionable" with a peculiar laugh. The aim of this article is twofold. On the one hand, this study seeks to delve into the existentialist dimension that can be found in Dylan's creative work since 1965, as well as to address the definition of the grotesque as a transhistorical artistic notion that disposes of an original imaginary based on monstrosity and excess. On the other hand, this research deals with an analysis of the grotesque dimension of existentialist inertia in the case of the three electric records published by Bob Dylan-Bringing It All Back Home, Highway 61 Revisited, Blonde on Blonde. Through a comparative study of his verses and the aesthetic notions arranged mainly by Wolfgang Kayser and Mijail Bajtín, a gradual taxonomy of the grotesque will be traced and applied to the lyrics that make up the three

Forma de citar:

Albarrán Ligero, J. (2020). La risa grotesca en la obra de Bob Dylan: análisis de la Bacanal y el Festín Carnavalesco en la trilogía folk-rock eléctrica. Ámbitos. Revista Internacional de Comunicación 50, pp. 128-144. doi:

10.12795/Ambitos.2020.i50.09 
componen los tres discos del músico estadounidense. El crudo realismo y el activismo político que Dylan había heredado de la primera generación del Folk Revival y del panorama left artist - Woody Guthrie, Pete Seeger, The Almanac Singers- fue evolucionando hasta superar el lenguaje parcialmente simbólico de sus primeros discos. Desde 1964, Dylan comenzaría un proceso de poetización nihilista en sus canciones que desembocaría en este ánimo grotesco.

Palabras clave: Bob Dylan, grotesco, trilogía eléctrica, existencialismo, Kayser, Bajtín. albums of the American musician. The crude realism and political activism that Dylan had inherited from the first generation of Folk Revival and the left artist scene-Woody Guthrie, Pete Seeger, The Almanac Singersgradually evolved to surpass the partially symbolic language of his first albums. From 1964, Dylan would begin a process of nihilistic poetization in his songs that would lead to this grotesque mood.

Keywords: Bob Dylan, grotesque, electric trilogy, existentialism, Kayser, Bajtín.

\section{INTRODUCCIÓN}

La gran mayoría de los críticos, teóricos y biógrafos de Bob Dylan -Coyle \& Cohen (2009), Scaduto (1972), Araguas (2014), (...) - coinciden en señalar que aquellos tres álbumes dorados del folk-rock que Dylan publicaría desde 1965 hasta 1966 -Bringin' It All Back Home (Dylan, 1965), Highway 61 Revisited (Dylan, 1965), Blonde on Blonde (Dylan, 1966) - se encuentran bañados por tendencias estéticas cercanas a las vanguardias europeas: dadaísmo, expresionismo, surrealismo (...). En esta época eléctrica, el lenguaje poético de Dylan se torna más plástico, simbólico y descarnado; una voz poética que dibujará - como ya observó Shelton (2011) - un mundo íntimo, secreto y oscuro surcado por tres grandes tendencias: "lo existencialista", "lo grotesco" y "Io burlesque". Hasta el año 1965, Dylan tanteó la respuesta de grandes incógnitas del ser humano a través de una estética realista, a veces con trazas de cierto simbolismo romántico - 'A Hard Rain Is a-Gonna Fall', 'Blowing in the Wind' -, pero tras la depuración del lenguaje poético de Another Side of Bob Dylan (Dylan, 1964), sería el mismo Dylan quien planteara los interrogantes a través de un deforme, órfico y festivo lenguaje. Los orígenes de este imaginario de lo "grotesco" se encuentran a menudo en un ánimo nostálgico promovido con frecuencia por una corriente filosófica que parecía impregnar el horizonte vital de Dylan por aquellas fechas: el existencialismo.

\subsection{Objetivos y metodología}

El primer objetivo de este artículo es profundizar en las nociones de lo "existencialista" y "lo grotesco" en su relación con la obra de Dylan, un desarrollo teórico imprescindible que nos permitirá acercarnos a nuestro segundo objetivo: el análisis de lo grotesco en la trilogía eléctrica de Dylan. Procederemos a rastrear esta dimensión de "lo existencialista" en el cantautor durante esta época (1965-1966), para proseguir con un acercamiento a la noción de "lo grotesco" con la que taxonomizar el ánimo estético de sus canciones en esta trilogía. Para la identificación de estas tendencias en su obra, nos hemos servido de un estudio cualitativo pormenorizado de sus canciones, atendiendo a los versos más significativos que muestren estas resonancias grotescas. Tras la identificación de estas direcciones estéticas, un estudio de contenido cuantitativo de los versos nos brindará un panorama general de esta opción estética grotesca en los tres discos eléctricos de Dylan. 


\section{LO EXISTENCIALISTA EN DYLAN: EL PRELUDIO DE LA RISA GROTESCA}

El existencialismo es una filosofía que inspira un posicionamiento estético, una opción creativa que transpira con intensidad en las composiciones de Dylan de este periodo. Sin embargo, el bardo de Duluth ha negado en varias ocasiones que fuera lector habitual y apasionado de Camus, Heidegger o Sartre, grandes exponentes existencialistas. Este periodo - de 1965 a 1966- se desvela como el más convulso a nivel personal y creativo en la carrera de Dylan. Todo apunta a que en el universo de Dylan el existencialismo se decanta desde la impronta del viaje y la aventura: en los callejones literarios y errantes del cantante y escritor Woody Guthrie -uno de sus últimos ídolos: Rumbo a la Gloria (2009), Una casa de tierra (2014) -, desde las carreteras propias del escritor Jack Kerouac que leyó con viveza -En el camino (1981), Los vagabundos del Dharma (1996) - y a través las siestas ocasionales en las estaciones de servicio; un posicionamiento ya inane de horas perdidas en la búsqueda del sentido último a través de la propia experiencia inmediata que proclamaban los poetas beats, tan caros a Dylan. Como ya apuntara Albert Camus en El mito de Sísifo (2018), el absurdo de la existencia del ser humano deviene por un sentimiento de nostalgia esencial que impregna una intuición de inadecuación en la vida humana; lo absurdo "es el divorcio entre el espíritu que desea y el mundo que decepciona, mi nostalgia de unidad, el universo disperso y la contradicción que los desencadena" (2018, p. 68). La conciencia preeminente de la muerte domina simbólicamente la emulsión de esta nostalgia existencialista, y Dylan contaba con todo el tiempo del mundo para pensar en la muerte. Este sentimiento de "nostalgia" es aquel que le desvela al ser humano su condición absurda, un sentimiento colindante con aquellos trazos románticos casados con cierto realismo que despuntan en la obra de Dylan desde su segundo disco: The Freewheelin' (Dylan, 1962). Como recuerda Sartre en El Existencialismo es un humanismo, para hacer soportable esta nostalgia, el ser humano debe proyectar una medida filosófica alejada del determinismo imperante, el ser humano es quien se define a sí mismo.

El ser humano ${ }^{1}$ es el único que no solo es tal y como él se concibe, sino tal y como él se quiere, y como se concibe después de la existencia, como se quiere después de este impulso hacia la existencia; el ser humano no es otra cosa que lo que él hace. Éste es el primer principio del existencialismo. (Sartre, 1980, p. 60)

Como también señala Camus, dentro de este absurdo vital, el ser humano es quien debe dotar de sentido a su propia existencia, el único capaz de abrazar la libertad desde la responsabilidad individual y moral de sus acciones: "But to live outside the law, you must be honest", Dylan clamaría esta máxima en 'Absolutely Sweet Mary' del disco Blonde on Blonde. En el famoso documental Don't Look Back (Pennebaker, 1967), Dylan y su entorno son filmados a través del cinema verité del director alemán D. Pennebaker durante su primera gran gira por Inglaterra en 1965. Durante una escena en la habitación del cantautor en el Hotel Savoy, el espectador encuentra al joven músico discutiendo enfadado con alguien por arrojar un vidrio por la ventana. El acusado se defiende: "Te digo que no he sido yo, tío. Pero, ¿quién soy yo? No soy nadie. No soy un gran cantante". Dylan replica visiblemente molesto: "Eh, iEh!" - grita-. "Tú eres quien dices que eres, tío" (Pennebaker, 1967). Tras el primer visionado de aprobación de la película, 
Dylan le exigiría a Pennebaker suprimir la escena de la discusión en el Hotel Savoy para el montaje final. Pennebaker se mostró contrario a esta decisión.

Dylan me pidió si podía eliminar la pelea en la habitación del hotel. No quería dar a entender que esa era la manera en la que vivía. Yo lo entendía, pero había otras consideraciones más importantes. "Tú eres lo que piensas que eres". iQué maravillosa cita! Es el concepto existencialista fundamental'2. (Shelton, 2011, p. 208)

De esta noción existencialista se desprende cierto individualismo tamizado por la visión del viaje romántico del hobo, del vagabundo músico; un individualismo que se mantendría alerta con una fiera independencia de medios de comunicación, leyes e instituciones; una ideología que moldearía y reconduciría de manera pacífica la desinhibición sexual y el naturalismo del movimiento hippie hacia la unidad fraternal en los años setenta. "Don't follow leaders/You watch the parkin' meters"', cantaría Dylan en 'Subterranean Homesick Blues', letra publicada en Bringin' All Back Home. Un concepto frecuente en biografías, análisis y artículos para definir esta época en la vida de Dylan es "angustia"; un término con unas connotaciones muy específicas, según el historiador francés Jean Delumeau.

El espanto, el pavor, el temor pertenecen al miedo; la inquietud, la ansiedad, la melancolía, más bien a la angustia. El primero lleva a lo conocido, la segunda a lo desconocido. El miedo tiene un objeto determinado al que se puede hacer frente. La angustia no lo tiene, y se la vive como una espera dolorosa ante un peligro tanto más temible cuanto no está claramente identificado: es un sentimiento global de inseguridad. Por eso es más difícil de soportar que el miedo. (Delumeau, 1989, p. 31)

Kierkegaard ya identifica esta angustia como una paradoja al señalar la conciencia de la finitud del ser humano con la infinitud que se le muestra. Como sostiene el filósofo danés, la angustia es producto de la propia posibilidad; en sentido más amplio, de aquella posibilidad que concede la propia libertad: "la angustia es el vértigo de la libertad" (1984, p. 88). Parecía que a Dylan le aquejara un desasosiego cercano a aquella angustia existencial, el concepto de desamparo cuando Dios ha muerto.

El existencialista suele declarar que el ser humano es angustia. Esto significa que el ser humano que se compromete y que se da cuenta de que es no solo el que elige ser sino también un legislador, que elige al mismo tiempo que a sí mismo a la humanidad entera, no puede escapar al sentimiento de su total y profunda responsabilidad (...). Todo ocurre como si, para todo ser humano, toda la humanidad tuviera los ojos fijos en lo que hace $y$ se ajustara a lo que hace. $Y$ cada ser humano debe decirse: ¿soy yo quien tiene derecho de obrar de tal manera que la humanidad se ajuste a mis actos? (Sartre, 1980, p. 65)

Como hemos apuntado, la conciencia de la muerte es un concepto esencial en la noción existencialista, como sostiene Camus, "[el absurdo] es al mismo tiempo conciencia de la muerte y su rechazo" (2018, p. 74). En la misma película Don't Look Back, Dylan mantiene una acalorada discusión con Horace Freeland Judson, un periodista londinense de la revista Time. Llegados a cierto punto, Dylan exclama: "Vas a morir. Y yo también. Me refiero a que los dos 
desapareceremos. El mundo se irá con nosotros. Pues bien, tú haz tu trabajo teniendo eso presente y decide lo serio que te tomas a ti mismo" (Pennebaker, 1967). Durante estos meses, existiría cierta incoherencia entre la vida y obra del cantante folk. Dylan se repetía a sí mismo y a la prensa que no encarnaba a ningún mesías, que solo podía ser "un guitarrista". Sin embargo, su imagen de poeta balsámico parecía elevarse en cada uno de sus discos y quizá esta noción consciente de adivino y mesías de masas acentuaba esta angustia existencial que se desprendía de aquella elección vital constante. Ante este dolor, esta angustia posibilitada por la propia libertad, el autor romántico solo puede excretar su padecimiento de este absurdo a través de la creatividad de su obra, del "desarreglo de sus sentidos" y de un "conocimiento de su alma", es decir, de sus "elecciones". Así, el artista se transforma en aquel vidente irrenunciable al que se refería Rimbaud en Cartas de un Vidente y que ya se intuía en la noción nietzschiana del poeta lírico.

El primer objeto de estudio de la persona que quiere ser poeta es su propio conocimiento, completo; se busca el alma, la inspecciona, la prueba, la aprende. Cuando ya se la sabe, tiene que cultivarla; lo cual parece fácil: en todo cerebro se produce un desarrollo natural; tantos egoístas se proclaman autores; ihay otros muchos que se atribuyen su progreso intelectual! - Pero de lo que se trata es de hacer monstruosa el alma: ia la manera de los comprachicos, vaya! Imagínese un hombre que se implanta verrugas en la cara y se las cultiva. Digo que hay que ser vidente, hacerse vidente. El poeta se hace vidente por un largo, inmenso y razonado desarreglo de todos los sentidos. Todas las formas de amor, de sufrimiento, de locura; busca por sí mismo, agota en sí todos los venenos, para no quedarse sino con sus quintaesencias. Inefable tortura en la que necesita de toda la fe, de toda la fuerza sobrehumana, por la que se convierte entre todos en el enfermo grave, el gran criminal, el gran maldito, -iy el supremo Sabio! - ¡Porque alcanza lo desconocido! ¡Porque se ha cultivado el alma, ya rica, más que ningún otro! Alcanza lo desconocido y, aunque, enloquecido, acabara perdiendo la inteligencia de sus visiones, ino dejaría de haberlas visto! Que reviente saltando hacia cosas inauditas o innombrables: ya vendrán otros horribles trabajadores; empezarán a partir de los horizontes en que el otro se haya desplomado. (Rimbaud, 1984, p. 89)

Esta reflexión romántica y maldita de Rimbaud se encuentra en el terreno movedizo del inconsciente, del Otro lacaniano, de las imágenes oníricas y del trance deforme que pertenecen al dominio dionisiaco nietzschiano (Nietzsche, 1969). Será a través de esta aprehensión del mundo, este "desarreglo de los sentidos", que la realidad (absurda en su concepción) se desfigurará también de manera formal hasta desembocar en la estética abyecta grotesca.

Quizá Dylan no hubiera llegado a esta posición vital de talante existencialista a través de la lectura de sus máximos exponentes, sino a través de una intuición y expresión vital inapelable: aquella que abraza la dolorosa noción de la libertad absoluta y sin ambages de la vida humana y la elección de sus bifurcaciones. Esta aparente dimensión absurda existencialista se agudiza en estos discos eléctricos, y concederá unos sólidos cimientos para la emergencia de la risa y la deformación ante la cruda realidad humana: la sombra rebelde de lo grotesco. 


\section{LO GROTESCO EN DYLAN (1965-1966)}

Aquello que se nombra abominable danza con la carcajada en los tres álbumes del periodo folkrock de Bob Dylan. Sobre todo en los dos últimos discos de este periodo - Highway 61 Revisited y Blonde on Blonde - se asiste a un desfile de imágenes oníricas y surrealistas, genuinamente distorsionadas, un absurdo collage esperpéntico que concentra una serie de rasgos comunes: una tonalidad oscura que se ha conocido como "lo grotesco".

\subsection{Los orígenes de lo grotesco y su incidencia artístico-teórica a lo largo de los siglos}

La estética grotesca es expresión de lo no canónico, de la monstruosidad. El origen etimológico de término "grotesco" se remonta a finales del siglo XV. Gracias a unas excavaciones en Roma en los subterráneos de las Termas de Tito, se descubrió un tipo de pintura ornamental desconocida hasta entonces a la que se denominó "grottesca», un derivado del sustantivo italiano "grotta"-gruta-. Estas pinturas presentaban una mezcla extravagante y excesiva entre lo real y lo fantástico, deformando la realidad en monstruos imaginarios e híbridos. El primer crítico de arte que esbozó un estudio teórico sobre el "grotesco" fue el famoso escritor Vasari, que emitió un juicio desfavorable sobre esta nueva pintura oscura. Vitruvio, también citado por Vasari, censuró la "barbaridad" de esta moda estética que consistía en "pintarrajear los muros con figuras monstruosas en lugar de pintar imágenes claras del mundo de los objetos" (Vitruvio citado en Bajtín, 2003, p. 29). Esta opción estética alcanzaría cierta popularidad artística debido a su atrevida originalidad.

El imaginario de "lo grotesco" acompaña al ser humano en su dimensión más cotidiana. Desde las comedias de Molière que bebían de manera directa de la comedia dell' arte italiana, lo grotesco nos acompaña en la literatura, arquitectura y pintura desde la Metamorfosis de Kafka, pasando por los cuentos y narraciones de Edgard Allan Poe - 'El aliento perdido' -, los primeros cuentos de Cortázar- 'El hijo del vampiro', 'Las manos que crecen'-, las gárgolas de las catedrales góticas, los relatos de E.T.A. Hoffman, de Joyce Carol Oates o las pinturas del periodo grotesco de Goya. Todas estas formas artísticas pareciera que conservan una serie de elementos comunes que giran en torno a la degradación y al horror, pero también, en muchas ocasiones, en torno a la risa, la ridiculez y la descarnada carcajada. Vasari en sus Vidas de los mejores arquitectos, pintores y escultores italianos ya describe lo grotesco como una pintura divertida que deforma la realidad de manera caprichosa a través de la fantasía extravagante del autor (Vasari citado en Polák, 2011, p. 40), y son otros muchos teóricos los que defienden la esencialidad humorística de la deformidad en lo grotesco como Justus Möser y el filósofo alemán Schlegel (Polák, 2011, pp. 43-44). Sin embargo, concitar una definición sintética de las variaciones semánticas de lo grotesco en la historia del arte ha perdurado como una tarea sumamente compleja debido a sus variantes estéticas, acentuadas por aquel hibridismo ambiguo y cambiante tan característico de lo grotesco. A partir del siglo XVI, esta opción estética se vuelve muy popular entre los artistas refinados y se extiende a la escultura, el grabado, la decoración de libros o la arquitectura. En el siglo XVIII se asiste a una concreción de formas y géneros de lo grotesco en el arte y el espectáculo. Durante el periodo de la llustración y 
Neoclasicismo, lo grotesco adquiere un nuevo significado satírico de denuncia que se añade a la deformación y a la risa ridícula como aquel recurso estético idóneo para denunciar las costumbres de la época, la tradición o el orden establecido. En el Romanticismo, lo grotesco se encontró ligado a los excesos de lo gótico (Guerrero-Strachan, 2007, p. 16). Como enmienda a la totalidad, Patrice Pavis en su Diccionario del teatro, define a lo grotesco como "la deformación significante de una forma conocida y reconocida como norma" (1998, p. 227), pero el estudioso obvia aquí una evidente noción humorística o satírica que parece aflorar en numerosas manifestaciones de lo grotesco a lo largo de la historia del arte. La estética grotesca cuestiona cualquier valoración estética, es decir, señala la esencia de la efemeridad de cualquier estilo (Polák, 2011). Esta negación de "un estilo definido" o definitivo se mostraba como tendencia indefinible en el imaginario dylaniano de estos tres discos eléctricos. La estética grotesca se presenta con frecuencia con una especial tendencia burlesca.

La doble noción de lo monstruoso y la risa para la deformación de la realidad parecen esenciales en la concepción original de lo grotesco. Pero, aun teniendo en cuenta estas categorías esenciales, la definición de la estética grotesca se muestra difusa. A continuación, estudiaremos dos consideraciones de esta perspectiva artística acuñadas por Wolfgang Kayser y Mijaíl Bajtín, para más tarde establecer una taxonomía gradual de "lo grotesco" y clasificar esta tendencia estética en las canciones de este periodo eléctrico de Dylan.

\subsection{La noción de lo grotesco según Wolfgang Kayser y Mijaíl Bajtín: hacia una taxonomía de lo grotesco}

Ambas concepciones teóricas de lo grotesco parten de diferentes supuestos históricos: Bajtín retrocede hasta al final del Medievo e inicios del Renacimiento para estudiar las características constitutivas de lo grotesco, mientras que el estudio de Kayser se fundamenta prioritariamente en la expresión romántica grotesca.

\subsubsection{La noción de lo grotesco según Wolfgang Kayser}

En su libro Lo Grotesco. Su configuración en pintura y literatura, Wolfgang Kayser (1906-1960) es uno de los primeros escritores que explora el concepto de "lo grotesco" como categoría "transhistórica", es decir, como categoría que se manifiesta de forma diferente y cambiante a lo largo de la historia. Kayser define de forma romántica lo grotesco como el desvelamiento cruel de la razón ante una existencia absurda.

Estamos (...) aterrados porque es nuestro mundo el que deja de ser de fiar (...). Lo grotesco infunde miedo a la vida más que miedo a la muerte (...) la progresiva disolución, que ha ocurrido desde el arte ornamental del Renacimiento; (...) la pérdida de identidad, el desorden "natural" en tamaño y forma, la suspensión de la categoría de los objetos, la destrucción de la personalidad, y la fragmentación del orden histórico. Las bestias apocalípticas emergen (...) los demonios nos poseen (...). Lo que se nos introduce se mantiene incomprensible, inexplicable e impersonal (...). Somos incapaces de orientarnos en un mundo alienado, porque es absurdo (...). Como género artístico, la tragedia se abre precisamente dentro de la esfera del sinsentido y de la absurdez de un significado 
profundo (...). El creador de lo grotesco no puede y no debe sugerir un significado (...). Lo grotesco es un juego con lo absurdo. Podría empezar de manera despreocupada (...). Pero debe también llevar al jugador lejos, privarle de su libertad, y hacerle sentir miedo de los fantasmas que tan frívolamente invoca (...) A pesar de toda la desesperanza y el horror inspiradas por las fuerzas oscuras (...) el verdadero retrato artístico afecta a una secreta liberación (...) La oscuridad se ha visto, los poderes ominosos descubiertos, las fuerzas incomprensibles convertidas (...) una interpretación de lo grotesco: una tentativa de invocar y subyugar los aspectos demoniacos del mundo. (Kayser citado en Shelton, 2011, p. 190)

Esta invocación de las sombras se desvela ante la inexcusable verdad del mundo. La abominable verdad de la existencia es lo que inhabilita el movimiento, y, por tanto, la música. Esta verdad inconcebible que hiere los ojos del ser humano ante un futuro incierto compromete los sentidos y amordaza toda voluntad de cambio, toda esperanza. La existencia se vuelve entonces insoportable, angustiosa y absurda. La evocación de las figuras demoniacas contra las que se lucha convierte la existencia en un tormento más ameno y llevadero por el propio hecho de reflejar y ridiculizar el absurdo de esta verdad, de esta certeza de la propia vida. Para el filósofo alemán, lo grotesco trata de transformar en decible lo indecible a través del ridículo. Esta concepción romántica del arte como vehículo y alivio de la verdad abominable ya la apunta Nietzsche en El origen de la tragedia.

Bajo la influencia de la verdad contemplada, el ser humano no percibe ya por todas partes más que lo horrible y absurdo de la existencia: comprende ahora lo que hay de simbólico en la suerte de Ofelia; reconoce la sabiduría de Sileno, el dios de los bosques, y el hastío le sube a la garganta. Y en este peligro inminente de la voluntad, el arte avanza entonces como un dios salvador que trae el bálsamo saludable: él sólo tiene el poder de transmutar ese hastío de lo que hay de horrible y absurdo en la existencia, en imágenes que ayudan a soportar la vida. Estas imágenes son "lo sublime", en el que el arte doma y sojuzga a lo horrible y "lo cómico", con el que el arte nos libra de la repulsión de lo absurdo. (1969, p. 54)

Este acto "sublime" y "cómico" a través del cual el arte se convierte en salvador de los sentidos se vuelve imprescindible ante esta verdad indecible, en la que se intuye la sombra de "lo grotesco". Baudelaire señala la importancia cómica de lo grotesco en estos términos extáticos que enlazan con la visión poética de Rimbaud, ya prefigurada por Nietzsche: "la risa causada por lo grotesco tiene en sí algo de profundo, de axiomático y de primitivo que se aproxima mucho más a la vida inocente y a la alegría absolutas que la risa originada por la comicidad de las costumbres" (Baudelaire, 1988, p. 34). Desde sus primeros discos, el humor ácido y polisémico resulta un rasgo distintivo en la obra de Dylan, pero en la trilogía eléctrica esta peculiaridad humorística se enlaza con un torrente onírico y deforme puramente imaginativo; un humor que traza las fronteras de "lo soportable" y que Vicente Araguas identifica con el surrealismo sardónico ante la risa corrosiva que baña con frecuencia canciones como 'Maggie's Farm' o 'Subterranean Homesick Blues'. Araguas - aun sin nombrar ninguna noción de lo grotesco- 
apunta asimismo una "salvación" surrealista, el humor se erige como una condición para "la soportabilidad" de la existencia.

A Dylan (a esa mujer [Maggie], a él mismo, a la canción, y no voy a hablar ahora de su impecable soporte musical, más cerca del "rock" que de la balada) lo salva el sentido del humor, tan necesario también en la poesía. Y no me estoy refiriendo, es claro, a lo que se ha dado en llamar "poesía festiva", un subgénero de efecto poético inmediato y muy poco más, que yo me refiero ahora a las altas cotas del humor quevediano, por no decir el desplegado por los surrealistas o el mismísimo T.S. Eliot. En todo caso el humor, más bien amargo, no falta en "Maggie's Farm". Cuál sea esa granja, donde todos mienten, todos explotan al prójimo, es lo de menos. Dylan, por supuesto, no desea trabajar en semejante sitio (nadie en su sano juicio querría hacerlo) donde los elementos reales devienen, por momentos, surreales. (Araguas, 2014, p. 257)

\subsubsection{La noción de lo grotesco según Mijail Mijáilovich Bajtín}

Por su parte, el teórico y lingüista ruso Mijaíl Mijáilovich Bajtín (1895-1975), en su libro La cultura popular en la Edad Media y el Renacimiento. El contexto de François Rabelais, concibe como uno de los rasgos característicos de lo grotesco a la "risa carnavalesca", una risa afilada pero también cómica, gozosa y desenfadada, en detrimento de la noción monstruosa y angustiosa, aquella sombra abominable que señala Kayser. Para Bajtín, el rasgo predominante del realismo grotesco es "la degradación, o sea la transferencia al plano material y corporal de lo elevado, espiritual, ideal y abstracto" (2003, p. 18), pero esta degradación no debe concebirse como una degeneración negativa o angustiosa, sino como una vuelta a los orígenes, como una "regeneración" alegre y tosca, una revitalización excesiva y descomunal (2003). Esta risa carnavalesca que mantiene el teórico ruso se traduce en "una risa popular y universal, donde todo el mundo ríe y se ríe de todo, radicalmente opuesta, por ello, a la risa romántica, bañada de ironía y sarcasmo ('sombría y maligna', según palabras del crítico ruso), que presenta el mundo como algo terrible y ajeno al ser humano" (Roas, 2011, p. 69). Para Bajtín, las esencias de la actitud carnavalesca son principalmente "una nueva actitud respecto a la realidad (el pasado se actualiza, se moderniza exageradamente), libre invención y actitud crítica o polémica con la tradición. En esta multiplicidad de tonos y voces, se mezcla lo sublime y lo vulgar, lo serio y lo cómico" (Zavala citada en Polák, 2011, p. 46). Esta integración entre lo sublime y lo popular o vulgar se encuentra en la obra de Dylan durante este periodo. Podemos identificar esta integración ultrajante en canciones como 'Temporarely Like Aquiles' o 'Desolation Row', como veremos a continuación.

\subsubsection{Hacia una definición integral de lo grotesco}

Las nociones de Kayser y Bajtín puede que reconozcan ambas un imaginario basado en la risa y la deformación, pero dejan entrever tonalidades divergentes. El teórico Petr Polák reconoce una diferenciación fundamental entre las concepciones esenciales de ambos teóricos.

En vez de elementos bajtianos como exceso, expansión, excentricidad, cuerpos gozosos y organización alegre de la comunidad nos encontramos con escasez, reducción, locura, 
seres híbridos y automatismo deshumanizado. A pesar de que en las dos [acepciones] encontramos un fondo común (sobre todo en el afán de recrear el mundo), es evidente que Bajtín pone el énfasis en la jovialidad, mientras que Kayser lo hace en la angustia vital. (Polák, 2011, p. 48)

Coincidimos con el teórico español David Roas, que considera que la noción de lo grotesco comprende por entero las dos dimensiones: la risa y lo abominable, y que, en el caso de lo grotesco, la distancia con el lector y el objeto humorístico viene identificada por "la hipérbole y la deformación de dicha categoría: de ese modo, los seres, objetos y situaciones representados, siempre se sitúan en una posición inferior al receptor" (Roas, 2011, p. 71). Una distinción similar apunta Baudelaire cuando señala la diferenciación antitética de lo grotesco -como lo cómico absoluto- frente a lo cómico significativo o cotidiano ${ }^{4}$, el primero ligado a la intuición, al vértigo y al acto primordial, mientras que el segundo se basa en estándares más superficiales y apologéticos: "lo cómico significativo es un lenguaje más claro, más fácil de comprender por el vulgo, y en particular, más fácil de analizar, al ser su elemento visiblemente dual: el arte y la idea moral" (Baudelaire, p. 35).

En definitiva, existe un arco, una graduación en la noción de lo grotesco cuyos polos quizá podrían constituir las dos nociones de lo grotesco expuestas: Kayser - con predominio de la angustia, el horror y la monstruosidad desgarradora- y Bajtín -con mayor componente de aquella risa carnavalesca, jovial y amena-. Ambas nociones de lo grotesco hacen gala de la deformación (a veces monstruosa) y la risa, pero con tendencia gradual hacia un extremo u otro. Podríamos denominar fácilmente la noción de lo grotesco en Kayser como "la Bacanal" y la definición de Bajtín como "el Festín Carnavalesco". Esta última noción, aunque linde con elementos cómicos, no se podría confundir nunca con el canon de "lo cómico" o "humorístico", puesto que existe un límite y una variación esencial en la risa ante "lo cómico" que ante "lo grotesco": la presencia - soterrada o no- de la desfiguración y la deformación monstruosa o excesiva.

\subsection{Lo grotesco en los tres discos eléctricos de Dylan}

A continuación, dispondremos los versos de estética grotesca encontrados en los tres discos pertenecientes al periodo eléctrico de Dylan - Bringin It All Back Home, Highway 61, Revisited, Blonde on Blonde- como cercanos a una de las dos tendencias. El resultado se observa en las tablas 1-3 (fig. 1-3).

\subsubsection{Lo grotesco en 'Bringing It All Back Home'}


Tabla 1

Tabla clasificatoria de los versos de tendencia grotesca en el disco Bringin It All Back Home

\begin{tabular}{|c|c|c|}
\hline Canción & Festín Carnavalesco & Bacanal \\
\hline $\begin{array}{l}\text { Subterranean Homesick } \\
\text { Blues }\end{array}$ & $\begin{array}{l}\text { Better stay away from those/ } \\
\text { That carry around a fire hose } \\
\text { (...) - Better jump down a } \\
\text { manhole/ Light yourself a } \\
\text { candle. }\end{array}$ & \\
\hline Outlaw Blues & $\begin{array}{l}\text { Don't ask me nothin' about } \\
\text { nothin'/ I just might tell you } \\
\text { the truth. }\end{array}$ & \\
\hline Bob Dylan 115 th Dream & $\begin{array}{l}\text { Just then a cop come down } \\
\text { the street crazy as a loon/ } \\
\text { They throws us all in jail for } \\
\text { carryin' harpoons. }\end{array}$ & \\
\hline $\begin{array}{l}\text { It's All Right Ma (I'm Only } \\
\text { Bleeding) }\end{array}$ & $\begin{array}{l}\text { While preachers preach of } \\
\text { evil fates/ Teachers teach } \\
\text { that knowledge waits/Can } \\
\text { lead to hundred-dollar } \\
\text { plates/ Goodness hides } \\
\text { behind its gates/But even the } \\
\text { president of the United } \\
\text { States/ Sometimes must } \\
\text { have/ To stand naked. } \\
\text { Although the masters make } \\
\text { the rules/ For the wise men } \\
\text { and the fools. }\end{array}$ & \\
\hline On the Road Again & $\begin{array}{l}\text { Your mama, she's a-hidin' } \\
\text { Inside the icebox. }\end{array}$ & $\begin{array}{l}\text { I get a face full of claws/ I ask } \\
\text { who's in the fireplace }\end{array}$ \\
\hline
\end{tabular}

Fuente: elaboración propia. 


\subsubsection{Lo grotesco en 'Highway 61 Revisited'}

Tabla 2

Tabla clasificatoria de los versos de tendencia grotesca en el disco Highway 61 Revisited

\begin{tabular}{|c|c|c|}
\hline Canción & Festín Carnavalesco & Bacanal \\
\hline Like A Rolling Stone & $\begin{array}{l}\text { At Napoleon in rags/ and the } \\
\text { language that he used. }\end{array}$ & \\
\hline Tombstone Blues & & $\begin{array}{l}\text { Mama's in the factory/ She } \\
\text { ain't got no shoes/ Daddy's } \\
\text { in the alley/ He's lookin' for } \\
\text { food./ I'm in the kitchen } \\
\text { With the tombstone blues. }\end{array}$ \\
\hline $\begin{array}{l}\text { It Takes a lot to Laugh, It } \\
\text { Takes a Train to Cry }\end{array}$ & & $\begin{array}{l}\text { Well, if I die on top of the hill/ } \\
\text { And if I don't make it you } \\
\text { know my baby will. }\end{array}$ \\
\hline From a Buick 6 & & $\begin{array}{l}\text { I got this graveyard woman, } \\
\text { you know she keeps my kid/ } \\
\text { But my soulful mama, you } \\
\text { know she keeps me hid/She's } \\
\text { a junkyard angel and she } \\
\text { always gives me bread/ Well, } \\
\text { if I go down dyin' you know } \\
\text { she bound to put a blanket on } \\
\text { my bed. }\end{array}$ \\
\hline Queen Jane Approximately & & $\begin{array}{l}\text { Now, when all the clowns } \\
\text { that you have commissioned/ } \\
\text { Have died in battle or in vain. } \\
\text { And you're sick of all this } \\
\text { repetition. }\end{array}$ \\
\hline Desolation Row & & $\begin{array}{l}\text { (Prácticamente toda la } \\
\text { canción y su leitmotiv): } \\
\text { They're selling postcards of } \\
\text { the hanging/ They're painting } \\
\text { the passports brown (...). }\end{array}$ \\
\hline
\end{tabular}

Fuente: elaboración propia. 


\subsubsection{Lo grotesco en 'Highway 61 Revisited'}

Tabla 3

Tabla clasificatoria de los versos de tendencia grotesca en el disco Blonde on Blonde

\begin{tabular}{|c|c|c|}
\hline Canción & Festín Carnavalesco & Bacanal \\
\hline Rainy Day Women \#12 \& 35 & $\begin{array}{l}\text { (Su concepto esencial y } \\
\text { factura): Everybody must } \\
\text { gets stone (...) }\end{array}$ & \\
\hline Visions of Johanna & & $\begin{array}{l}\text { When the jelly-faced women } \\
\text { all sneeze/Hear the one with } \\
\text { the mustache say, : "Jeeze/ I } \\
\text { can't find my knees";/ Oh, } \\
\text { jewels and binoculars hang } \\
\text { from the head of the mule } \\
\text { But these visions of Johanna, } \\
\text { they make it all seem so cruel. }\end{array}$ \\
\hline $\begin{array}{l}\text { Soon or Later One of Us Must } \\
\text { know }\end{array}$ & & $\begin{array}{l}\text { An' I told you, as you clawed } \\
\text { out my eyes/ } \\
\text { That I never really meant to } \\
\text { do you any harm }\end{array}$ \\
\hline I Want You & $\begin{array}{l}\text { The guilty undertaker sighs/ } \\
\text { (...) The drunken politician } \\
\text { leaps. }\end{array}$ & \\
\hline $\begin{array}{l}\text { Stuck Inside of Mobile with } \\
\text { the Memphis Blues Again }\end{array}$ & $\begin{array}{l}\text { Mona tried to tell me/ To stay } \\
\text { away from the train line/ She } \\
\text { said that all the railroad men } \\
\text { Just drink up your blood like } \\
\text { wine. }\end{array}$ & $\begin{array}{l}\text { Grandpa died last week } \\
\text { And now he's buried in the } \\
\text { rocks/ But everybody still } \\
\text { talks about how/ Badly they } \\
\text { were shocked. }\end{array}$ \\
\hline Temporarely like Achiles & $\begin{array}{l}\text { Achilles is in your alleyway/ } \\
\text { He don't want me here, he } \\
\text { does brag/ He's pointing to } \\
\text { the sky/ And he's hungry, like } \\
\text { a man in drag. }\end{array}$ & \\
\hline
\end{tabular}




\begin{tabular}{|c|c|c|}
\hline Absolutely Sweet Marie & $\begin{array}{l}\text { Well, I got the fever down in } \\
\text { my pockets/ The Persian } \\
\text { drunkard, he follows me/ } \\
\text { Yes, I can take him to your } \\
\text { house but I can't unlock it. }\end{array}$ & \\
\hline Obviously 5 Believers & $\begin{array}{l}\text { Fifteen jugglers/ Five } \\
\text { believers/ Five believers } \\
\text { All dressed like men } \\
\text { Tell yo' mama not to worry } \\
\text { because/ They're just my } \\
\text { friends. }\end{array}$ & \\
\hline Sad Eye Lady of the Lowlands & & $\begin{array}{l}\text { But with the sea at your feet/ } \\
\text { and the phony false alarm. } \\
\text { And with the child of a } \\
\text { hoodlum/ wrapped up in } \\
\text { your arms. }\end{array}$ \\
\hline
\end{tabular}

Fuente: elaboración propia.

\subsubsection{Síntesis de los resultados sobre lo grotesco en Bringin' It All Back Home, Highway 61} Revisited y Blonde on Blonde

Los rastros de lo grotesco se observan en veinte canciones de la trilogía del rock de Dylan. Esta tendencia a la deformación encuentra referencia en 5 canciones de las 11 que componen Bringing It All Back Home. La presencia del Festín Carnavalesco de Bajtín, más amable, gozoso y cómico, es preeminente en los versos grotescos del álbum, con tan solo algunas líneas discordantes del tema 'On the Road Again' que pertenecen a la Bacanal monstruosa de Kayser. En cuanto al segundo álbum, Highway 61 Revisited, lo grotesco se muestra en 6 de las 9 canciones que forman el disco. En Highway 61 Revisited, la Bacanal de Kayser evoca la mayoría de las imágenes poéticas del álbum, con la excepción del verso "At Napoleon in rags", que discurre en Like A Rolling Stone, más cercano a la carcajada festiva y excesiva del Festín Carnavalesco. La Bacanal domina con tal potencia este álbum que se desenvuelve en mismo leitmotiv: las imágenes absurdas que desfilan en la última canción del disco: 'Desolation Row'. Blonde on Blonde presenta trazos de lo grotesco en 9 de sus 14 canciones. Blonde expresa una integración equitativa de las dos tendencias. La Bacanal se percibe en 4 canciones, aunque se observa con mayor protagonismo el Festín Carnavalesco -6 canciones-, aquel ánimo desenfadado y cómico que se aleja de lo siniestro y se acerca a la risa por la risa, siempre predispuesta a la broma excesiva y al ultraje de la mofa. Al igual que ocurriera con 'Desolation Row', el disco comienza con una canción que concentra, en el núcleo de su concepción y factura, el exceso y el gozo propio del Festín Carnavalesco: 'Rainy Day Women \#12 \& 35'. Como panorámica general, observamos que las señas grotescas del Festín Carnavalesco se encuentran 
en 10 canciones, mientras que la monstruosidad y la angustia de la Bacanal se expresa en 12 temas a lo largo de este periodo eléctrico.

En 'Stuck Inside of Mobile with the Memphis Blues Again' Dylan corrobora de manera explícita estos necesarios anteojos de la deformación y la monstruosidad para acercarse a esta noción abyecta y necesaria de "lo grotesco": "Now the rainman gave me two cures/ Then he said, "Jump right in"/ The one was Texas medicine/ The other was just railroad gin/ An' like a fool I mixed them/ An' it strangled up my mind/ An' now people just get uglier/ An' I have no sense of time" (Blonde on Blonde, 1966).

Prácticamente disuelto en lo grotesco, encontramos una tonalidad nacida en las sombras del circo, del vaudeville, del misterio del espectáculo de máscaras y sombras chinas: la ridiculización o pantomima. Frecuentemente, la dimensión cómica de lo grotesco en Dylan se sirve de un imaginario literario e histórico que el músico reconduce hacia el esperpento grotesco Napoleón, Aquiles, Enza Pound, T.S Elliot, Queen Mary-. Pero esta deformación estética presenta una esencia muy particular, una textura como de lienzo rugoso: un ademán de cabaret con los trazos acuosos de Touluose Lautrec. El componente cómico en lo grotesco de Dylan se sirve de la estética teatral del burlesque. El término burlesque proviene del concepto italiano burlesco, un término que gira en torno a lo ridículo, lo paródico y el disparate. Desde la comedia del arte, la poesía burlesca de Quevedo, hasta Cervantes con El Quijote, el concepto de lo burlesco ha denigrado los estándares literarios y socialmente aceptados hasta derivar en un género teatral basado en la ridiculización y pantomima a finales del siglo XIX de estética muy singular: vedettes, magos de cabaret, adivinos, tullidos y un elenco freak que se extiende desde las sombras y que acompañan en su dimensión estética de manera natural al concepto de lo grotesco. Dylan siempre ha sugerido cierta debilidad por la estética circense, por el misterio del espectáculo de variedades de principios de siglo XX y por el baile vedettiano, los trucos de magia y las inquietantes virtudes de los lisiados de feria ambulante. Quizá el mayor ejemplo ilustrativo de la dimensión grotesca/burlesca en Dylan durante este periodo lo alcance 'Desolation Row'. En aquel festival de monstruos que es nuestra sociedad, cercano a la fiesta, a la noche, al secreto y al sinsentido de la desolación: "Now the moon is almost hidden/ the stars are beginning to hide/ The fortune telling lady/ has even taken all her things inside/ All except for Cain and Abel and the hunchback of Notre Dame/ everybody is making love or else expecting rain/ And the Good Samaritan, he's dressing, he's getting ready for the show. He's going to the carnival tonigh on Desolation Row" (Highway 61 Revisited, 1966).

\section{CONCLUSIONES}

La expresión de lo grotesco a través de la historia del arte se muestra difusa y especialmente heterogénea. Aun considerando sus dos rasgos esenciales, la risa y la deformación excesiva, la definición acotada de una tendencia imaginativa que subvierte y satiriza cualquier estándar artístico escapa con frecuencia a la sistematización que sintetice la complejidad de un concepto tan ambiguo. Considerando la polarización de lo grotesco en dos nociones acuñadas por dos de los teóricos más influyentes en este campo -la Bacanal (más cercana a la concepción romántica 
de Wolfgang Kayser) y el Festín Carnavalesco — basada en el festín cómico excesivo de Mijaíl Bajtín - sostenemos que las letras que pertenecen a esta etapa eléctrica de Dylan se internan en lo grotesco a través del humor y los excesos del Festín Carnavalesco preeminentemente en Bringing It All Back Home. En Highway 61, el imaginario grotesco se oscurece desvelando una tendencia más expresionista y romántica, para más adelante utilizar invariablemente ambas nociones de lo grotesco en Blonde on Blonde, siempre con un talante cercano al imaginario burlesque.

La Bacanal, aquella risa sórdida, abominable, angustiosa y sarcástica de Kayser parece que se ajustara con mayor comodidad a la tonalidad de la mayoría de canciones de la trilogía del rock de Dylan: el desfile malogrado, deforme y surrealista; aunque la noción de Bajtín, aquel festival del exceso y la risa satírica se encuentra en mayor medida, casi en igualdad de condiciones y calidad, en las canciones de este periodo eléctrico. El crudo realismo cercano al activismo político que Dylan había heredado de la primera generación del Folk Revival y del panorama leftartist -Woody Guthrie, Pete Seeger, The Almanac Singers - se diluye en este periodo eléctrico hacia la risa grotesca. Esta tendencia grotesca se acentúa desde Bringin It All Back Home hasta alcanzar el culmen de riqueza en Blonde on Blonde, donde los monstruos distorsionan la razón y los sentidos. Tras este periodo, y determinado por su accidente de moto en 1966, el imaginario de Dylan se alejaría de esta incontenible impronta grotesca y volvería su creatividad hacia unos estándares más apegados a la enorme tradición folk y a su imaginario simbólico.

\section{Referencias}

Araguas, Vicente (2014). El mundo poético de Bob Dylan. Tesis Doctoral. Universidad de Coruña: Coruña, España. Recuperado de: https://ruc.udc.es/dspace/bitstream/handle/2183/13835/Araguas_Vicente_TD_2014.pdf [Consultado el 13 de marzo de 2020].

Bajtín, Mijaíl (2003). La cultura popular en la edad media y el renacimiento. El contexto de Francois Rabelais. Madrid: Alianza. Extraído de: https://ayciiunr.files.wordpress.com/2014/08/bajtinmijail-la-cultura-popular-en-la-edad-media-y-el-renacimiento-rabelais.pdf [Consultado el 3 de abril de 2020].

Baudelaire, Charles (1988). Lo cómico y la caricatura. Madrid: Visor.

Camus, Albert (2018). El mito de Sisifo. Madrid: Alianza.

Coyle, Michael \& COHEN, Debra Rae (2009). "Blonde on Blonde". En Detmaar, Kevin, The Cambridge Companyon to Bob Dylan. Cambridge: Cambridge University Press, pp. 143-149.

Delumeau, Jean (1989). El miedo en Occidente. Madrid: Taurus.

Dylan, Bob (1962). The Freewheelin' Bob Dylan. New York: Columbia.

Dylan, Bob (1964). Another Side of Bob Dylan. New York: Columbia Records.

Dylan, Bob (1965). Bringin It All Back Home. New York: Columbia Records.

Dylan, Bob (1965). Highway 61 Revisited. New York: Columbia Records.

Dylan, Bob (1966). Blonde on Blonde. New York: Columbia Records. 
Guerrero-Strachan, Santiago Rodríguez (2007). “Las varias caras de lo grotesco”. En Antología del cuento grotesco. Madrid: Espasa-Calpa.

Guthrie, Woody (2009). Rumbo a la Gloria. Woody Guthrie. Memorias. Barcelona: Global Rhythm.

Guthrie, Woody (2014). Una casa de tierra. Madrid: Anagrama.

Kayser, Wolfgang (2010). Lo grotesco: su realización en literatura y pintura. Madrid: Antonio Machado.

Kerouac, Jack (1981). En el camino. Barcelona: Bruguera.

Kerouac, Jack (1996). Los vagabundos del Dharma. Barcelona: Anagrama.

Kierkegaard, Soren (1984). El concepto de la angustia. Trad. Demetrio Gutiérrez Rivero. Barcelona: Orbis.

Nietzsche, Friedrich (1969). El origen de la tragedia. Madrid: Espasa-Calpe.

Pavis, Patrice (1998). Diccionario del teatro. Barcelona: Paidós.

Pennebaker, D.A (1967). Don't Look Back. Pennebaker Associated.

Polák, Petr (2011). "El arte grotesco a través de los siglos". En El esperpento valleinclaniano en el contexto del arte grotesco europeo. Brno: Masarykovauniverzita, pp. 39-64

Rimbaud. Arthur (1984). Una temporada en el infierno. Seguido de lluminaciones y Cartas del Vidente. Traducción de Ramón Buenaventura. Madrid: Hiperión.

Roas, David (2011). Tras los límites de lo real. Madrid: Páginas de espuma.

Sartre, Jean-Paul (1980). El existencialismo es un humanismo. Barcelona: Orbis.

Scaduto, Antony (1972). Bob Dylan. An intimate biography. Londres: W.H. Allen.

Shelton, Robert (2011). No Direction Home. The Life \& Music of Bob Dylan. Londres: Omnibus Press

\section{Notas}

1“Hombre” en la edición original.

${ }^{2}$ Traducción del autor.

3"No sigas a líderes/vigila tu parquímetro".

${ }^{4}$ Esta distinción es similar en graduación extática - de aquellos rasgos más desenfadados y populares a aquellos más primitivos y esencialistas - aunque no en concepto básico, ya que el crítico francés no otorga expresamente la dimensión monstruosa o gozosa a su noción de "cómico ordinario" o "cómico absoluto", aunque sí concede cierto grado de degradación y ultraje a este último: "Lo cómico sólo puede ser absoluto en relación con la humanidad caída" (Baudelaire, 1988, p. 35). 